\title{
A Quantitative Analysis of Fish Consumption and Stroke Risk
}

Article in American Journal of Preventive Medicine · December 2005

DOI: 10.1016/j.amepre.2005.07.002 · Source: PubMed

CITATIONS

90

9 authors, including:

Joshua T Cohen

Tufts Medical Center

168 PUBLICATIONS 3,814 CITATIONS

SEE PROFILE

\section{George Gray}

George Washington University Milliken Inst...

71 PUBLICATIONS 1,838 CITATIONS

SEE PROFILE

\section{READS}

13
Penny M Kris-Etherton

Pennsylvania State University

196 PUBLICATIONS $\quad 13,211$ CITATIONS

SEE PROFILE

Ariane König

University of Luxembourg

29 PUBLICATIONS $\quad \mathbf{1 , 7 1 5}$ CITATIONS

SEE PROFILE

Some of the authors of this publication are also working on these related projects:

Project

Project
SCHOOL FUTURES: Introducing future-oriented systems thinking into the luxembourgish school curriculum View project

Public health View project

All content following this page was uploaded by Ariane König on 17 November 2017. 


\section{A Quantitative Analysis of Fish Consumption and Stroke Risk}

Colleen Bouzan, MS, Joshua T. Cohen, PhD, William E. Connor, MD, Penny M. Kris-Etherton, PhD, George M. Gray, PhD, Ariane König, PhD, Robert S. Lawrence, MD, David A. Savitz, PhD,

Steven M. Teutsch, MD

Abstract: Although a rich source of n-3 polyunsaturated fatty acids (PUFAs) that may confer multiple health benefits, some fish contain methyl mercury $(\mathrm{MeHg})$, which may harm the developing fetus. U.S. government recommendations for women of childbearing age are to modify consumption of high-MeHg fish to reduce $\mathrm{MeHg}$ exposure, while recommendations encourage fish consumption among the general population because of the nutritional benefits. The Harvard Center for Risk Analysis convened an expert panel (see acknowledgments) to quantify the net impact of resulting hypothetical changes in fish consumption across the population. This paper estimates the impact of fish consumption on stroke risk. Other papers quantify coronary heart disease mortality risk and the impacts of both prenatal MeHg exposure and maternal intake of n-3 PUFAs on cognitive development.

This analysis identified articles in a recent qualitative literature review that are appropriate for the development of a dose-response relationship between fish consumption and stroke risk. Studies had to satisfy quality criteria, quantify fish intake, and report the precision of the relative risk estimates. The analysis combined the relative risk results, weighting each proportionately to its precision. Six studies were identified as appropriate for inclusion in this analysis, including five prospective cohort studies and one case-control study (total of 24 exposure groups). Our analysis indicates that any fish consumption confers substantial relative risk reduction compared to no fish consumption (12\% for the linear model), with the possibility that additional consumption confers incremental benefits (central estimate of $2.0 \%$ per serving per week).

(Am J Prev Med 2005;29(4):347-352) @ 2005 American Journal of Preventive Medicine

\section{Introduction}

$\mathrm{T}$ The pioneering work of Bang and Dyerberg ${ }^{1,2}$ first raised the possibility that fish consumption might offer protection against the risk of stroke. They found that for some types of stroke, the Inuit had a lower mortality risk compared to Danish whites. Evidence also suggests that n-3 polyunsaturated fatty acids (PUFAs) may protect against other diseases, such as coronary heart disease (CHD) ${ }^{3}$ and that it may be

From the Harvard Center for Risk Analysis, Harvard School of Public Health (Bouzan, Cohen, Gray, König), Boston, Massachusetts; Division of Endocrinology, Diabetes and Clinical Nutrition, Oregon Health Sciences University (Connor), Portland, Oregon; Department of Nutritional Sciences, Pennsylvania State University (Kris-Etherton), University Park, Pennsylvania; Department of Health Policy and Management, Bloomberg School of Public Health, Johns Hopkins University (Lawrence), Baltimore, Maryland; Department of Epidemiology, School of Public Health, University of North Carolina (Savitz), Chapel Hill, North Carolina; and Department of Outcomes Research and Management, Merck \& Co., Inc. (Teutsch), West Point, Pennsylvania

Address correspondence and reprint requests to: Joshua T. Cohen, $\mathrm{PhD}$, Harvard Center for Risk Analysis, 718 Huntington Avenue, Boston MA 02115. E-mail: cohenj@hsph.harvard.edu. important to fetal development. ${ }^{4}$ On the other hand, fish is a leading source of exposure to methyl mercury $(\mathrm{MeHg})$, an environmental contaminant that may adversely affect fetal development.

Because of the potential for $\mathrm{MeHg}$ in fish to adversely affect fetal development, the U.S. Food and Drug Administration (FDA) and the U.S. Environmental Protection Agency issued a joint advisory in March 2004 recommending that pregnant women modify their fish consumption. ${ }^{5}$ However, depending on how they are implemented, interventions to decrease exposure to $\mathrm{MeHg}$ may decrease overall fish consumption. For example, Oken et al. ${ }^{6}$ reported a $17 \%$ decrease in fish consumption among pregnant women following the release of the FDA's $2001 \mathrm{MeHg}$ advisory. Moreover, other members of the population could decrease their fish consumption as an unintended consequence of risk-management actions targeting $\mathrm{MeHg}$ exposure among women of childbearing age.

In order to understand the possible public health ramifications of alternative risk-management actions, it is necessary to quantify potential health benefits and 
risks associated with plausible changes in population fish consumption patterns. This paper evaluates the impact of fish consumption on stroke incidence. This analysis quantifies stroke relative risk as a function of fish consumption (servings per week). These effects can then be compared to other risks and benefits associated with changes in fish consumption.

Three other papers in this issue develop doseresponse relationships between prenatal n-3 PUFA intake and $\mathrm{IQ}$ prenatal $\mathrm{MeHg}$ exposure and IQ and between adult fish consumption and CHD mortality. ${ }^{7-9}$ A fifth paper, also in this volume, combines these results to estimate the aggregate health effects of hypothetical changes in fish consumption on public health. ${ }^{10}$

Strokes fall into two main categories: ischemic and hemorrhagic. Ischemic strokes are caused by a blockage of arteries leading to the brain. They result from atherosclerosis of the carotid and cerebral arteries plus thrombosis. ${ }^{11}$ Hemorrhagic stroke results from a weakened blood vessel that ruptures and bleeds into the surrounding brain tissue. ${ }^{11,12}$ Each year in the United States, approximately 700,000 people experience a new or recurrent stroke; for about 170,000 of these individuals, that stroke is fatal. Of all strokes in this country, $88 \%$ are ischemic and the remainder are hemorrhagic. ${ }^{11-13}$

Dietary intake of n-3 PUFAs may reduce stroke risk through a range of biochemical mechanisms, including diminution of platelet aggregation, ${ }^{14-17}$ inhibition of the 5-lipoxygenase pathway, ${ }^{18}$ and reduction of plasma fibrinogen concentrations, ${ }^{19,20}$ among others.

To assess quantitatively the risks and benefits of fish consumption, the Harvard Center for Risk Analysis convened an expert panel, as described in the acknowledgments. A series of papers aims to quantify various health risks associated with $\mathrm{MeHg}$ exposure and the health benefits associated with n-3 PUFA intake so that they can be compared. This paper investigates the benefit of n-3 PUFA intake on stroke risk. The goal is the development of a dose-response relationship between intake of n-3 PUFA and stroke to inform the analysis of the public health effects of changes in fish consumption. The remainder of this paper has two parts. The first describes the use of epidemiologic study results to quantify the dose-response relationships. Studies included in this analysis are a subset of those identified in a recent qualitative review of the literature on this topic. ${ }^{21}$ The last section presents the discussion.

\section{Stroke Relative Risk Associated with Fish Consumption or n-3 PUFA Intake}

This section describes the development of doseresponse relationships for the impact of fish consumption on total stroke risk (i.e., fatal and nonfatal strokes).

\section{Literature Review}

This analysis augments a literature search of Medline with the findings of a recent review conducted by Wang et al. ${ }^{21}$ to identify studies of fish consumption and stroke risk. The analysis limits attention to a subset of the observational studies identified in that review. In brief, Wang et al. ${ }^{21}$ first identified abstracts from public indexes (Medline and Embase) and summaries of the literature (Cochrane Central Register of Controlled Trials, 4th quarter, 2002). Wang et al..$^{21}$ also consulted with an expert panel to identify studies. They eliminated from consideration studies reported only as abstracts or in letters, and studies that followed subjects with non cardiovascular disease (CVD)-related conditions. Other studies omitted were those following an inappropriate or pediatric population (aged $<19$ years); studies not mentioning n-3 PUFA intake; studies involving $\mathrm{n}-3$ PUFA intakes $>6 \mathrm{~g} /$ day; prospective studies $<4$ weeks in duration; studies with fewer than five subjects in the treatment group receiving n-3 PUFAs; studies not reporting outcomes of interest; and studies that did not report intake rates for n-3 PUFAs (or fish) (e.g., studies that expressed exposure only in terms of n-3 PUFA biomarker levels). Wang et al. ${ }^{21}$ summarize the observational studies they identified that report on stroke in table 3-38 of their report.

For this analysis, attention is limited to studies appropriate for the purpose of quantitative dose-response evaluation. Three additional criteria are imposed. First, the studies had to quantify risk relative to a no-intake or very-low-intake reference group (fish consumption of less than one serving per month). Second, this analysis includes only those studies with designs rated by Wang et al. ${ }^{21}$ as either "A" (least bias; results are valid) or "B" (susceptible to some bias, but not sufficient to invalidate the results), but not "C" (significant bias that may invalidate the results). Finally, attention is limited to studies that estimated risk for both fatal and nonfatal strokes.

Three randomized controlled trial (RCT) studies were omitted that otherwise satisfied the criteria described above ${ }^{22-24}$ (see tables 3-21, 3-23, and 3-36 in Wang et al. $\left.{ }^{21}\right)$. The information from these studies was not combined with the information from the observational studies because the dosages (n-3 PUFA intakes of 0.27 to $6.3 \mathrm{~g} /$ day), the exposure vehicle (capsules), and the characteristics of the subjects (patients with previous coronary disease of some type or multiple cardiovascular risk factors) limit the comparability of the two designs. This analysis does not analyze the RCT studies on their own because the three data points that they represent are insufficient for quantitative analysis.

Table 1 summarizes the five prospective cohort studies and one case-control study included in this analysis. Of the studies listed in table 3-38 of Wang et al., ${ }^{21}$ this 


\begin{tabular}{|c|c|c|c|c|c|c|}
\hline Study $(\text { year })^{\text {ref }}$ & Population & $\begin{array}{l}\text { Population } \\
\text { country }\end{array}$ & $\begin{array}{l}\text { Follow-up } \\
\text { (years and } \\
\text { person-years) }\end{array}$ & \multicolumn{2}{|c|}{ Fish intake } & $\begin{array}{l}\text { Total stroke RR } \\
\text { (CI) }\end{array}$ \\
\hline \multirow{3}{*}{$\begin{array}{l}\text { He }(2002)^{25} \\
\text { (Health } \\
\text { Professional } \\
\text { Follow-up Study) }\end{array}$} & \multirow{3}{*}{$\begin{array}{l}43,671 \text { males aged } 40-75 \\
\text { years with no stroke at } \\
\text { baseline }\end{array}$} & \multirow[t]{3}{*}{ U.S. } & 12 & $<1 / \mathrm{mo}$ & 0 & 1 \\
\hline & & & \multirow[t]{2}{*}{462,024} & $1-3 / \mathrm{mo}$ & 0.5 & $0.73(0.48-1.10)$ \\
\hline & & & & $1 / \mathrm{wk}$ & 1.0 & $0.74(0.52-1.04)$ \\
\hline \multirow{5}{*}{$\begin{array}{l}\text { Iso }(2001)^{26} \\
\quad \text { (Nurses' Health } \\
\text { Study) }\end{array}$} & \multirow{5}{*}{$\begin{array}{l}79,839 \text { females aged } 30- \\
55 \text { years with no stroke } \\
\text { at baseline }\end{array}$} & \multirow[t]{5}{*}{ U.S. } & 14 & $<1 /$ mo & 0 & 1 \\
\hline & & & \multirow[t]{4}{*}{$1,086,261$} & $1-3 / \mathrm{mo}$ & 0.5 & $0.93(0.65-1.34)$ \\
\hline & & & & $1 / \mathrm{wk}$ & 1.0 & $0.78(0.55-1.12)$ \\
\hline & & & & $2-4 / \mathrm{wk}$ & 3.0 & $0.73(0.47-1.14)$ \\
\hline & & & & $\geq 5 / w k$ & 6 & $0.48(0.21-1.06)$ \\
\hline \multirow{3}{*}{$\begin{array}{l}\text { Gillum }(1996)^{27} \\
\text { (NHANES I } \\
\text { Epidemiologic } \\
\text { Follow-up Study) }\end{array}$} & \multirow{3}{*}{$\begin{array}{l}2351 \text { white females aged } \\
45-74 \text { years with no } \\
\text { stroke at baseline } \\
2059 \text { white males aged } \\
45-74 \text { years with no } \\
\text { stroke at baseline }\end{array}$} & \multirow{3}{*}{ U.S. } & \multirow{3}{*}{ Up to $16^{\mathrm{b}}$} & $<1 /$ wk & 0.5 & $1.27(0.83-1.96)$ \\
\hline & & & & $1 / \mathrm{wk}$ & 1.0 & $1.23(0.79-1.91)$ \\
\hline & & & & $>1 /$ wk & 4.0 & $0.85(0.49-1.46)$ \\
\hline \multirow{4}{*}{$\begin{array}{l}\text { Orencia }(1996)^{28} \\
\quad \text { (Chicago Western } \\
\text { Electric Study) }\end{array}$} & \multirow{4}{*}{$\begin{array}{l}1847 \text { males aged } 40-55 \\
\text { years with no stroke at } \\
\text { baseline }\end{array}$} & \multirow[t]{4}{*}{ U.S. } & 30 & 0 & 0 & 1 \\
\hline & & & \multirow[t]{3}{*}{46,426} & $1-17 \mathrm{~g} /$ day & 0.6 & $0.98(0.61-1.59)$ \\
\hline & & & & $18-34 \mathrm{~g} /$ day & 1.8 & $0.94(0.59-1.52)$ \\
\hline & & & & $\geq 35 \mathrm{~g} /$ day & 4.7 & $1.26(0.74-2.16)$ \\
\hline \multirow[t]{5}{*}{ Caicoya $(2002)^{29}$} & \multirow{5}{*}{$\begin{array}{l}440 \text { cases and } 473 \\
\text { controls aged } 40-85 \\
\text { years }\end{array}$} & \multirow[t]{5}{*}{ Spain } & \multirow{5}{*}{$\begin{array}{l}\text { Not applicable: } \\
\text { case-control }\end{array}$} & $0 \mathrm{~g} /$ day & 0 & 1 \\
\hline & & & & $1-22.5 \mathrm{~g} /$ day & 0.8 & $0.30(0.12-0.78)$ \\
\hline & & & & $23-45 \mathrm{~g} /$ day & 2.4 & $0.44(0.18-1.41)$ \\
\hline & & & & $46-90 \mathrm{~g} /$ day & 4.8 & $0.59(0.24-1.47)$ \\
\hline & & & & $91-250 \mathrm{~g} /$ day & 11.9 & $0.76(0.27-2.10)$ \\
\hline
\end{tabular}

${ }^{a}$ Estimated as the midpoint of the lower and upper ends of the range provided in the original study. If only a lower bound is provided, we assume that the upper bound is seven servings per week. If the original study expressed fish consumption in grams, we assume that one serving is $100 \mathrm{~g}$. ${ }^{\mathrm{b}}$ Study does not specify total years of follow-up.

CI, confidence interval; NHANES, National Health and Nutrition Examination Survey; RR, relative risk.

analysis includes all but four. Kinjo et al. ${ }^{30}$ was eliminated because Wang et al. ${ }^{21}$ judged its design to be poor (grade of "C"); Yuan et al. ${ }^{31}$ was eliminated because they reported on stroke mortality risk rather than stroke incidence risk; Morris et al. ${ }^{32}$ was eliminated because the reference group included individuals consuming less than one serving of fish per week; and Keli et al. ${ }^{33}$ was eliminated because the reference group included subjects consuming as much as $20 \mathrm{~g}$ fish/day, or more than one serving per week. Relative risk values reported in Table 1 reflect adjustment for potential confounders.

Finally, note that there is qualitative evidence suggesting that n-3 PUFA intake may increase the risk of hemorrhagic stroke, ${ }^{34-36}$ and thus dilute the benefit associated with a lower ischemic stroke risk. For the purpose of evaluating the benefits associated with n-3 PUFA intake, however, only the net impact on stroke incidence is relevant. In any case, the importance of this phenomenon to the U.S. population is not clear. For example, although Bang and Dyerberg ${ }^{37}$ reported that higher levels of n-3 PUFA intake increased bleeding tendency among Inuits (a condition that could increase hemorrhagic stroke risk), that population has much higher n-3 PUFA intake rates $(14 \mathrm{~g} / \text { day })^{42}$ than do Americans, among whom n-3 PUFA intake (eicosapentaenoic acid 20:5 n-3 [EPA] and decosahexaenoic acid 22:6 n-3 [DHA]) averages 0.1 to $0.2 \mathrm{~g} /$ day. ${ }^{38}$ (Note that the values for the Inuit are based on dietary surveys carried out in the early 1970s.)

\section{Dose-Response Methodology}

To develop the dose-response relationships between the relative risk of stroke and fish consumption, this analysis first combines the results from all of the relevant studies into a single data set. That is, the analysis combines the 21 nonreference group, relativerisk values reported by the five studies listed in Table 1 .

Second, this analysis standardized the reported fish consumption rates expressed as ranges (e.g., " 1 to 3 fish servings per month") by converting them into point estimates expressed as average fish servings consumed per week. When the lower and upper bounds are specified for a range, the range's midpoint is used (two fish servings per month in the 
Table 2. Relationship between fish consumptions and total stroke relative risk

\begin{tabular}{llllr}
\hline Analysis & Parameter & $\mathbf{R}^{2}$ & $\mathbf{\Delta R R}$ & \multicolumn{1}{c}{$\mathbf{9 5 \%} \mathbf{C I}$} \\
\hline Linear regression & Intercept & $3.4 \%$ & -0.12 & -0.25 to 0.01 \\
& Servings/week & & -0.020 & -0.066 to 0.027 \\
Quadratic regression & Intercept & & -0.095 & -0.26 to 0.072 \\
& Servings/week & $5.0 \%$ & -0.048 & -0.16 to 0.065 \\
\hline
\end{tabular}

CI, confidence interval; RR, relative risk.

preceding example, amounting to around 0.5 servings per week). If no upper bound is specified (e.g., " $>5$ servings per week"), the assumed upper bound is seven servings per week. For studies that express fish consumption in terms of grams per day, this analysis assumes that $100 \mathrm{~g}$ of fish is equivalent to one serving (Table 1).

Finally, this analysis regresses these observations (SAS procedure GLM, version 9.1 for Windows, SAS Institute, Cary NC, 2004), weighted by their statistical precision, against fish consumption (servings per week). It is assumed that statistical precision is proportional to the squared width of the log-transformed relative-risk confidence interval. This measure of precision is used because the parameter estimates in a logistic regression are normally distributed after $\log$ transformation. Hence, the width of the log-transformed confidence interval is proportional to the estimate's standard error, and the square of the width is proportional to the estimate's variance. The variance, in turn, is inversely proportional to the weight assigned an observation when aggregating data for a meta-analysis.

The analysis considers both a linear and quadratic functional form for the dose-response relationship. For the purpose of including the one case-control study listed in Table 1 in this analysis, the relative risk estimates for different fish-consumption groups are treated in the same way as relative-risk estimates were reported in the prospective cohort studies.

\section{Results}

Table 2 summarizes the parameter estimates for stroke risk. The linear regression of total stroke risk (ischemic plus hemorrhagic) against fish consumption suggests a modest benefit (Figure 1). The results indicate that fish consumption reduces stroke risk by $12 \%$ (95\% confidence interval $[\mathrm{CI}]$ ranging from a $25 \%$ reduction in risk to a $1 \%$ increase) compared to no fish consumption. The central estimate for the incremental reduction in stroke risk per fish serving per week is $2.0 \%$, with a $95 \%$ CI ranging from a $6.6 \%$ reduction in risk per serving per week to a $2.7 \%$ increase in risk per serving per week. Because the quadratic regression does not explain the data substantially better than the linear regression $\left(\mathrm{R}^{2}\right.$ of $5.0 \%$ for the quadratic regression vs
$3.4 \%$ for the linear regression), that model is disregarded.

\section{Discussion}

The results in Table 2 suggest that any fish consumption results in a notable decrease in stroke risk compared to no fish consumption, with the $95 \%$ confidence interval for the intercept term just bordering zero. The incremental contribution to further risk reduction associated with additional fish consumption is more ambiguous, with a confidence interval that includes zero. Nonetheless, because the center of this distribution is somewhat less than zero (a risk reduction of $2.0 \%$ per serving per week), an incremental benefit remains plausible.

A relatively large benefit associated with any level of fish consumption is consistent with Driss et al., ${ }^{15}$ who provided mechanistic evidence for a benefit at relatively low intake rates. That clinical trial showed that intake of $150 \mathrm{mg} /$ day EPA (a rate compatible with the average American fish consumption) reduces platelet aggregation.

Our findings can be compared to the dose-response relationship developed using results from a recent meta-analysis conducted by $\mathrm{He}$ et al. ${ }^{39} \mathrm{He}$ et al. ${ }^{39}$ did not report a dose-response relationship, but instead

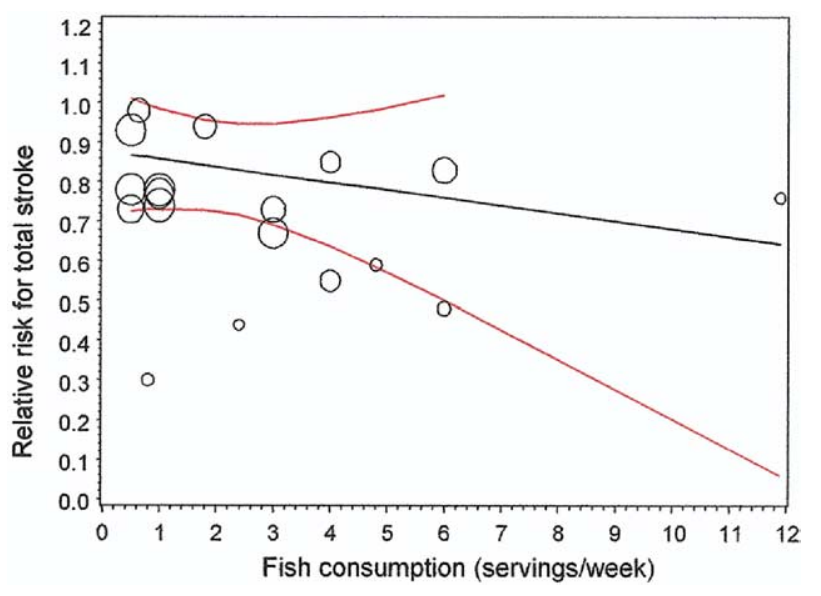

Figure 1. Regression of total stroke risk versus fish consumption. Note: The area of each data point is proportional to its statistical weight. The upper and lower bands denote the $95 \%$ confidence interval on the mean of the predicted value. 
reported discrete estimates of risk for four different consumption rates. They concluded that compared to individuals consuming fish less than once per month, relative risk for stroke was $0.91(95 \% \mathrm{CI}=0.79-1.06)$ for subjects consuming fish one to three times per month, $0.87(95 \% \mathrm{CI}=0.77-0.98)$ for subjects consuming fish once per week, $0.82(95 \% \mathrm{CI}=0.72-0.94)$ for subjects consuming fish two to four times per week, and 0.69 $(95 \% \mathrm{CI}=0.54-0.88)$ for subjects consuming fish five or more times per week. A weighted regression through these four relative risk estimates (assigning a fish consumption rates of $0.5,1.0,3.0$, and 6.0 servings per week to each group, respectively) yields an intercept of 0.92 (i.e., some fish consumption reduces risk by $8 \%$, compared to no fish consumption) and a slope of -0.036 (i.e., increasing fish consumption by one serving per week reduces stroke risk by $3.6 \%$ ). Recall that the linear regression in this paper yielded an intercept of 0.88 $(-0.25$ to +0.01$)$ and a slope of $-0.02 \quad(95 \%$ $\mathrm{CI}=-0.067$ to +0.027$)$. Given the breadth of these confidence intervals, the findings of this study and the He et al. ${ }^{39}$ analysis are not inconsistent.

Although these findings and the He et al. ${ }^{39}$ metaanalysis findings are consistent, it is worth noting that inclusion criteria represent a major difference between these two studies. Two studies were omitted from our analysis that were included by He et al. ${ }^{39}$ (Keli et al. ${ }^{33}$ and Morris et al. ${ }^{32}$ ) because the fish consumption rates in the reference groups were too high for the purpose of evaluating risks relative to "those who never consumed fish or ate fish less than once per month." In addition to these two studies, this analysis omitted Yuan et al. ${ }^{31}$ and Sauvaget et al. ${ }^{40}$ because they analyzed risk for stroke mortality rather than stroke incidence. In addition, Sauvaget et al. ${ }^{40}$ was not included in the Wang et al. ${ }^{21}$ review. Finally, this analysis included one study ${ }^{29}$ that He et al. ${ }^{39}$ omitted because it used a case-control design.

Most of the risk reduction identified here is from ischemic stroke. Although there is suggestive biological and epidemiologic evidence that n-3 intake may increase hemorrhagic stroke risk, that possibility could not be substantiated in this study. At most, because hemorrhagic stroke represents only a modest proportion of all strokes, any increase would simply temper the overall benefit from reductions in ischemic events. If such an increase in hemorrhagic stroke risk does exist, it is apparent largely at high n-3 PUFA intake levels that are atypical for the U.S. population. The fact that the large RCT study described by Marchioli et al. ${ }^{23}$ did not find an increase in stroke risk at relatively high n-3 PUFA intakes (0.85 g/day EPA plus DHA), however, casts some doubt on even this possibility. In any case, the relatively small number of hemorrhagic strokes, compared to ischemic strokes, limits the potential impact of this putative risk. Finally, and most importantly, any countervailing tendency is reflected in this analysis, which uses data for total stroke risk. An online supplement to this manuscript ${ }^{41}$ discusses the biological mechanisms that may influence the role of n-3 intake on these two categories of stroke.

Although this analysis cannot explain the pathophysiologic events underlying the beneficial impact of fish intake on stroke risk, it indicates that the largest incremental benefit accrues at relatively low levels of fish intake, and that incremental fish consumption confers no substantial additional benefits. The general pattern for this dose-response relationship is similar to that found for the association between fish intake and CHD risk among individuals with no prior history of this disease (see König et al. ${ }^{7}$ ). As in the case of CHD, a low level of fish consumption appears to confer substantial protection against stroke risk. In addition, this analysis identified a relatively modest incremental benefit associated with additional fish consumption. This pattern is not necessarily inconsistent with the absence of an identified incremental fish consumption benefit in the case of stroke given the limited data available for this evaluation. The similarity in the shape of the dose-response relationships for stroke and CHD is consistent with the hypothesis that a similar mechanism (e.g., reduction in platelet aggregation) may play a role in the impact of fish intake on both diseases.

The expert panel convened by the Harvard Center for Risk Analysis for this project was chaired by Steven M. Teutsch. In addition to William Connor, Penny Kris-Etherton, Robert Lawrence, and David Savitz, who are co-authors on this paper, the panel consisted of David C. Bellinger, PhD (Department of Neurology, Children's Hospital, Boston MA), and Bennett A. Shaywitz, MD (Department of Pediatrics and Neurology, Yale University, New Haven CT).

This work was supported by a grant from the National Food Processors Association Research Foundation (NFPA-RF) and the Fisheries Scholarship Fund. Member companies of the NFPA-RF may be affected by the findings of research that funded my participation on the panel that wrote this paper.

\section{References}

1. Bang HO, Dyerberg J. The composition of food consumed by Greenlandic Eskimos. Acta Med Scand 1973;200:69-73.

2. Bang HO, Dyerberg J. Hemostatic function and platelet polyunsaturated fatty acids in Eskimos. Lancet 1979;2:433-5.

3. Bang HO, Dyerberg J, Nielsen AB. Plasma lipid and lipoprotein pattern in Greenlandic West-Coast Eskimos. Lancet 1971;1:1143-5.

4. Helland IB, Smith L, Saarem K, Saugstad OD, Drevon CA. Maternal supplementation with very long chain n-3 fatty acids during pregnancy and lactation augments children's IQ at 4 years of age. Pediatrics 2003;111:E39-44.

5. U.S. Department of Health and Human Services, U.S. Environmental Protection Agency. What you need to know about mercury in fish and shellfish, 2004. Available at: www.cfsan.fda.gov/ dms/admehg3.html. Accessed December 2004.

6. Oken E, Kleinman KP, Berland WE, Simon S, Rich-Edwards JW, Gillman MW. Decline in fish consumption among pregnant women after a national mercury advisory. Obstet Gynecol 2003;102:346-51. 
7. König A, Bouzan C, Cohen JT, et al. A quantitative analysis of fish consumption and coronary heart disease mortality. Am J Prev Med 2005;29:335-46.

8. Cohen JT, Bellinger DC, Shaywitz BA. A quantitative analysis of prenatal methyl mercury exposure and cognitive development. Am J Prev Med 2005;29:353-65.

9. Cohen JT, Bellinger DC, Connor WE, Shaywitz BA. A quantitative analysis of prenatal intake of n-3 polyunsaturated fatty acids and cognitive development. Am J Prev Med 2005;29:366-74.

10. Cohen JT, Bellinger DC, Connor WE, et al. A quantitative risk benefit analysis of changes in population fish consumption. Am J Prev Med 2005;29:325-34.

11. American Stroke Association. About stroke, 2003. Available at: www.stroke association.org. Accessed December 2003.

12. Internet Stroke Center. About stroke Vol. 2003. Washington University School of Medicine, 2003. Available at: www.strokecenter.org. Accessed December 2003.

13. American Heart Association. Heart disease and stroke statistics. Dallas TX, 2003. Available at: www.americanheart.org/downloadable/heart/ 1040391091015HDS_Stats_03.pdf. Accessed December 2003.

14. Amin-Zaki L, Majeed MA, Clarkson TW, Greenwood MR. Methylmercury poisoning in Iraqi children: clinical observations over two years. BMJ 1978;1:613-6.

15. Driss F, Vericel E, Lagarde M, Dechavanne M, Darcet P. Inhibition of platelet aggregation and thrombocane synthesis after intake of small amount of icosapentaenoic acid. Thromb Res 1984;36:389-96.

16. Dyerberg J, Bang HO. Hemostatic function and platelet polyunsaturated fatty acids in Eskimo. Lancet 1979;2:433-5.

17. Terrano T, Hirai A, Hamazaki T, et al. Effect of oral administration of highly purified eixosapentaenoic acid on platelet function, blood viscosity and red cell deformability in healthy human subjects. Atherosclerosis 1983;46:321-31.

18. Lee TH, Hoover RL, Williams JD, et al. Effect of dietary enrichment with eicosapentaenoic and docosahexaenoic acids on in vitro neutrophil and monocyte leukotriene generation and neutrophil function. N Engl J Med 1985;312:1217-24.

19. Hostmark AT, Bjerkedal T, Keierulf P, Flaten H, Ulshagen K. Fish oil and plasma fibrinogen. BMJ 1988;297:180-1.

20. Wilhelmsen L, Svardsudd K, Korsan-Bengtsen K, Larsson B, Welin L, Tibblin G. Fibrinogen as a risk factor for stroke and myocardial infarction. N Engl J Med 1984;311:501-5.

21. Wang C, Chung M, Balk E, et al. Effects of omega-3 fatty acids on cardiovascular disease. Boston MA: Tufts-New England Medical Center EPC. Prepared for Agency for Healthcare Research and Quality, Rockville MD, 2004 (contract 290-02-0022). Available at: www.ahrq.gov/clinic/ epcsums/o3cardsum.htm. Accessed April 2004.

22. Sacks FM, Stone PH, Gibson M, Silverman DI, Rosner B, Pasternak RC. Controlled trial of fish oil for regression of human coronary atherosclerosis. J Am Coll Cardiol 1995;25:1492-8.

23. Marchioli R, Barzi F, Bomba E, et al. Early protection against sudden death by $n-3$ polyunsaturated fatty acids after myocardial infarction: time-course analysis of the results of the Gruppo Italiano per lo Studio della Soprav- vivenza nell'Infarto Miocardico (GISSI)-Prevenzione. Circulation 2002;105:1897-903.

24. Bemelmans WJ, Broer J, Feskens EJ, et al. Effect of an increased intake of alpha-linolenic acid and group nutritional education on cardiovascular risk factors: the Mediterranean Alpha-linolenic Enriched Groningen Dietary Intervention (MARGARIN) study. Am J Clin Nutr 2002;75:221-7.

25. He K, Rimm EB, Merchant A, et al. Fish consumption and risk of stroke in men. JAMA 2002;288:3130-6.

26. Iso H, Rexrode KM, Stampfer MJ, et al. Intake of fish and omega-3 fatty acids and risk of stroke in women. JAMA 2001;285:304-12.

27. Gillum RF, Mussolino ME, Madans JH. The relationship between fish consumption and stroke incidence: the NHANES I Epidemiologic Follow-up Study (National Health and Nutrition Examination Survey). Arch Intern Med 1996;156.

28. Orencia AJ, Daviglus ML, Dyer AR, Shekelle RB, Stamler J. Fish consumption and stroke in men: 30-year findings of the Chicago Western Electric Study. Stroke 1996;27.

29. Caicoya M. Fish consumption and stroke: a community case-control study in Asturias, Spain. Neuroepidemiology 2002;21:107-14.

30. Kinjo Y, Beral V, Akiba S, et al. Possible protective effect of milk, meat and fish for cerebrovascular disease mortality in Japan. J Epidemiol 1999;9:268-74.

31. Yuan JM, Ross RK, Gao YT, Yu MC. Fish and shellfish consumption in relation to death from myocardial infarction among men in Shanghai, China. Am J Epidemiol 2001;154:809-16.

32. Morris MC, Manson JE, Rosner B, Buring JE, Willett WC, Hennekens CH. Fish consumption and cardiovascular disease in the Physicians' Health Study: a prospective study. Am J Epidemiol 1995;142:166-75.

33. Keli SO, Feskens EJ, Kromhout D. Fish consumption and risk of stroke. The Zutphen Study. Stroke 1994;25:328-32.

34. Iso H, Stampfer MJ, Manson JE, et al. Prospective study of fat and protein intake and risk of intraparenchymal hemorrhage in women. Circulation 2001;103:856-63.

35. Pedersen HS, Mulvad G, Seidelin KN, Malcom GT, Bourdreau DA. N-3 fatty acids as a risk factor for hemorrhagic stroke. Lancet 1999;353:812-3.

36. Shimamoto T, Iso H, Iida M, Komachi Y. Epidemiology of cerebrovascular disease: stroke epidemic in Japan. J Epidemiol 1996;6:S43-7.

37. Bang HO, Dyerberg J. The bleeding tendency in Greenland Eskimos. Dan Med Bull 1980;27:202-5.

38. Kris-Etherton PM, Taylor DS, Yu-Poth S, et al. Polyunsaturated fatty acids in the food chain in the United States. Am J Clin Nutr 2000;71(suppl 1):179S-88S.

39. He K, Song Y, Daviglus ML, et al. Fish consumption and incidence of stroke: a meta-analysis of cohort studies. Stroke 2004;35:1538-42.

40. Sauvaget C, Nagano J, Allen N, Grant EJ, Beral V. Intake of animal products and stroke mortality in the Hiroshima/Nagasaki Life Span Study. Int J Epidemiol 2003;32:536-43.

41. Bouzan C. Evidence that n-3 PUFAs increase hemorrhagic stroke risk. Boston MA: Harvard Center for Risk Analysis, 2004. Available at: www. hcra.harvard.edu. Accessed June 2004.

42. Bang HO, Dyerberg J, and Sinclair HM. The composition of the Eskimo food in north western Greenland. American Journal of Clinical Nutrition $33: 2657-61$. 